\title{
Lymphotoxin Alpha Measurement
}

National Cancer Institute

\section{Source}

National Cancer Institute. Lymphotoxin Alpha Measurement. NCI Thesaurus. Code C132375.

The determination of the amount of lymphotoxin alpha in a biological sample. 